\title{
Proses Sintering dan Karakterisasi pada Keramik Zircon Silikat (ZrSiO4)
}

\author{
Suprapedi $^{1}$, dan Mulyadi ${ }^{2, *}$ \\ ${ }^{\text {I }}$ Program Studi Magister Teknik Informatika, Universitas Dian Nuswantoro, Semarang \\ ${ }^{2}$ Teknik Mesin, Universitas Pamulang, Tangerang Selatan, Banten \\ E-mail: *dosen01545@unpam.ac.id
}

Masuk : 10 Maret 2020

Direvisi : 2 April 2020

Disetujui : 15 April 2020

\begin{abstract}
Abstrak: Zircon silikat $\left(\mathrm{ZrSiO}_{4}\right)$ merupakan jenis keramik berbasis oksida dan banyak dipergunakan sebagai bahan refraktori. Untuk mengetahui proses sintering yang optimal maka pada penelitian ini di gunakan bahan alami yaitu zirkon silikat. Preparasi bahan dilakukan melalui proses pencampuran menggunakan wet milling dengan alat ball mill selama 12 jam. Selanjutnya dilakukan proses pengeringan dan pencetakan membentuk sampel pelet. Pada proses pencetakan tekanan yang diberikan pada saat proses pencetakan sampel menggunakan gaya sebesar $10000 \mathrm{kgf}$. Selanjutnya dilakukan proses sintering (pembakaran) dengan variasi suhu $1200^{\circ} \mathrm{C}, 1300^{\circ} \mathrm{C}$, dan $1400^{\circ} \mathrm{C}$ menggunakan tungku listrik dan ditahan selama 60 menit. .Sampel pelet yang telah disintering dilakukan pengujian antara lain : densitas, kekerasan, dan kuat tekan. Hasil karakterisasi keramik zircon silikat $\left(\mathrm{ZrSiO}_{4}\right)$ menunjukkan bahwa densitas maksimum terdapat pada sampel dengan suhu sintering $1400^{\circ} \mathrm{C}$ dengan nilai $3,93 \mathrm{~g} / \mathrm{cm}^{3}$. Dalam pengujian kekerasan menunjukan nilai kekerasan tertinggi dicapai pada suhu $1400^{\circ} \mathrm{C}$ dengan nilai $570 \mathrm{Hv}$. Sedangkan pada pengujian kuat tekan nilai tertinggi dicapai dengan suhu sintering $1400^{\circ}$ $\mathrm{C}$ mendapat angka kuat tekan sebesar $792,63 \mathrm{~kg} / \mathrm{cm}^{2}$
\end{abstract}

Kata kunci: zircon silikat $\left(\mathrm{ZrSiO}_{4}\right)$, sintering, refraktori, densitas, kekerasan, kuat tekan.

\begin{abstract}
Zircon silicate (ZrSiO4) is a type of oxide-based ceramic and is widely used as a refractory material. To determine the optimal sintering process, this study used a natural material, namely zircon silicate. Material preparation was carried out through a mixing process using wet milling with a ball mill for 12 hours. Furthermore, the drying and printing processes are carried out to form pellet samples. In the printing process, the pressure applied during the printing process uses a force of $10000 \mathrm{kgf}$. Furthermore, the sintering process is carried out with temperature variations of 1200OC, 1300OC, and 1400OC using an electric furnace and held for 60 minutes. The samples of pellets that have been sintered are tested, including: density, hardness and compressive strength. The characterization results of zircon silicate ceramics $(\mathrm{ZrSiO} \neg 4)$ show that the maximum density is found in the sample with a sintering temperature of $1400{ }^{\circ} \mathrm{C}$ with a value of $3.93 \mathrm{~g} / \mathrm{cm} 3$. In hardness testing, it shows that the highest hardness value is reached at a temperature of $1400{ }^{\circ} \mathrm{C}$ with a value of $570 \mathrm{Hv}$. Whereas in the compressive strength test the highest value was achieved with a sintering temperature of $1400^{\circ} \mathrm{C}$ getting a compressive strength figure of $792.63 \mathrm{~kg} / \mathrm{cm} 2$
\end{abstract}

Keywords: zircon silicate (ZrSiO4), sintering, refractory, density, hardness, compressive strength.

\section{PENDAHULUAN}

Pembuatan keramik pada zaman dahulu hanya dilakukan dengan membakar satu bahan saja, yaitu dengan lempung (tanah liat). Seni dan Industri keramik telah berlangsung sejak ribuan tahun yang lalu, proses pembuatan keramik pada zaman dahulu dengan cara dibakar menggunakan bahan dan peralatan sederhana. Bahan yang dipakai adalah feldspar (seperti batuan beku asam, dan granit), tanah liat dan lempung [1]. Hal ini disebabkan karena pengetahuan tentang keramik belum menandai.

Seiring dengan perkembangan ilmu bahan maka proses pembuatan keramik dari tahun ke tahun mengalami kemajuan. Pada awalnya diproduksi secara tradisional dari mineral alam, namun sekarang kegunaan keramik sudah bermacam-macam fungsinya, dulu hanya digunakan sebagai barang pecah belah, gerabah. Sekarang telah 
menjadi industri yang cukup besar dengan aplikasi kegunaan seperti keramik poselin salah satu bahan isolator listrik, komponen mekanik,bahan refraktori dan lainnya.

Untuk meningkatkan kualitas produk keramik tradisional ini, perlu dilakukan rekayasa sifat mekanis guna meminimalisir cacat atau rusak saat proses produksi. Material industri keramik mengalami perkembangan pesat. Perkembangan tersebut meliputi didalam struktur, komposisi, sifat-sifat fisis dan mekanik. Zirkon silikat tergolong jenis material alam yang memiliki kandungan Zirkonia dan silika yang tinggi. Material keramik yang memiliki kandungan zirkonia dan silika yang tinggi dapat dimanfaatkan sebagai bahan tahan panas, karena memiliki suhu lebur yang tinggi [2]. Proses sintering adalah salah satu tahapan pada produksi keramik, dan kualitas suatu produk keramik dapat tergantung pada proses sintering. Jadi proses sintering merupakan suatu proses konsolidasi serbuk hingga menjadi padatan yang kuat [3, 4]. Setiap material memiliki tingkatan suhu sintering yang berbeda, semakin tinggi suhu leburnya maka semakin tinggi suhu sinteringnya [4]. Parameterparameter yang mempengaruhui suhu sintering antara lain $[4,5]$ : tingkat kemurnian dari bahan dan tingkat kehalusan bahan $[5,6]$. Penelitian proses sintering material keramik telah banyak dilakukan diantaranya peneltian yang berkaitan sintering keramik alumina $\left(\mathrm{Al}_{2} \mathrm{O}_{3}\right)$ yaitu proses sinteringnya dilakukan pada suhu sangat tinggi yaitu pada suhu $1500-1700^{\circ} \mathrm{C}$ karena alumina mempunyai titik lebur mencapai $2050^{\circ} \mathrm{C}$ [7]. Pada tulisan ini dibahan tentang proses sintering keramik zirkon silikat serta mengetahui pengaruhnya variasi suhu sintering terhadap karakteristik keramik zirkon silikat.

\section{METODOLOGI}

Bahan baku yang digunakan antara lain serbuk zirkon silikat, bahan ini lagsung digiling menggunakan ball mill denag media milling aquades dan waktu milling selama 12 jam. Kemudian sampel di keluarkan dari ball mill dan dikeringkan di pengering pada suhu $110^{\circ} \mathrm{C}$ sampai sampel menjadi kering. Selanjutnya serbuk yang telah kering di gerus menggunakan mortar tangan dan diayak lolos ayakan 200 mesh. Selanjutnya serbuk yang telah halus di campur dengan perekat Poly Vinyl Alcohol (PVA) sebanyak $5 \%$ berat. Kemudian dicetak membentuk pelet berdiameter $18 \mathrm{~mm}$ dengan gaya tekan sebesar $10000 \mathrm{kgf}$. Pelet yang dihasilkan selanjutnya di sintering menggunakan tungku listrik dengan laju kenaikan suhu $10^{\circ} \mathrm{C}$ per menit, suhu sintering divariasikan yaitu 1200,1300 dan $1400^{\circ} \mathrm{C}$ dan ditahan untuk masing-masing suhu sintering selama 60 menit.

Sampel yang telah disintering dilakukan pengukuran densitas yang diukur massa sampel dengan timbangan digital, dan diukur dimensi tebal dan diameter sampel, kemudian dihitung volume silinder. Selanjutnya dihiyung nilai densitas dengan persamaan :

$$
\text { Densitas }=\rho=\frac{\text { Massa }}{\text { Volume }} \mathrm{g} / \mathrm{cm}^{3}
$$

Sedangkan kekerasan vickers sampel diukur menggunakan microhardness tester, dan dilanjutkan dengan pengukuran kuat tekan, perhitungan kuat tekan di lakukan menggunakan persamaan :

$$
\begin{gathered}
\text { Gaya tekan }(\mathrm{F}) \\
\begin{array}{c}
\text { Kuat tekan = -------- } \mathrm{kgf} / \mathrm{cm}^{2} \\
\text { Luas penampang }(\mathrm{A})
\end{array}
\end{gathered}
$$

\section{HASIL DAN PEMBAHASAN}

\section{Hasil uji densitas Zircon Silikat $\left(\mathrm{ZrSiO}_{4}\right)$.}

Hasil penelitian yang penulis lakukan, maka nilai densitas setelah proses sintering dapat diperlihatkan pada Gambar 1. 
40 | Suprapedi, dkk., Proses Sintering dan Karakterisasi pada....

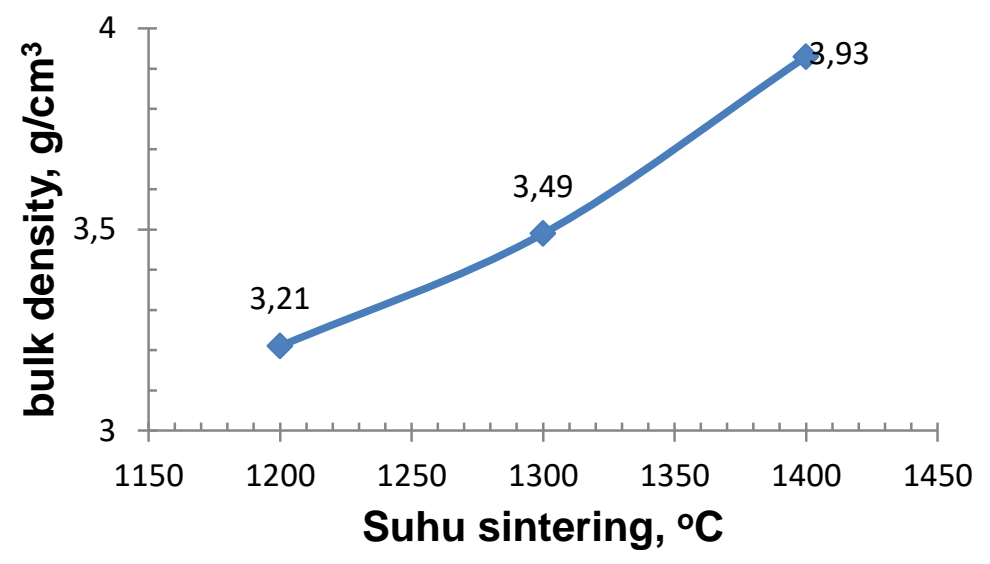

Gambar 1. Grafik Hasil Pengujian Densitas.

Dari Gambar 1 grafik di atas terlihat bahwa nilai densitas meningkat seiring dengan bertambahnya suhu sintering. Nilai densitas maksimum di peroleh pada suhu $1400^{\circ} \mathrm{C}$ dengan waktu sintering selama 60 menit dengan nilai $3,93 \mathrm{~g} / \mathrm{cm}^{3}$. Sedangkan densitas teoritis untuk zirkonsilikat adalah 4,30 g/cm3 [2]. Bilai hasil dari penelitian ini dibandingkan dengan densiitas teoritis masih dibawahnya, dan dikatakan densifikasinya baru tercapai $91 \%$.

\section{Hasil Uji Kekerasan Zircon Silikat $\left(\mathrm{ZrSiO}_{4}\right)$}

Dari hasil penelitian yang penulis lakukan maka hasil dapat di ketahui dengan pengujian kekerasan menggunakan microhardness tester. Hasil pengujian kekerasan vikers diperlihatkan seperti pada Gambar 2.

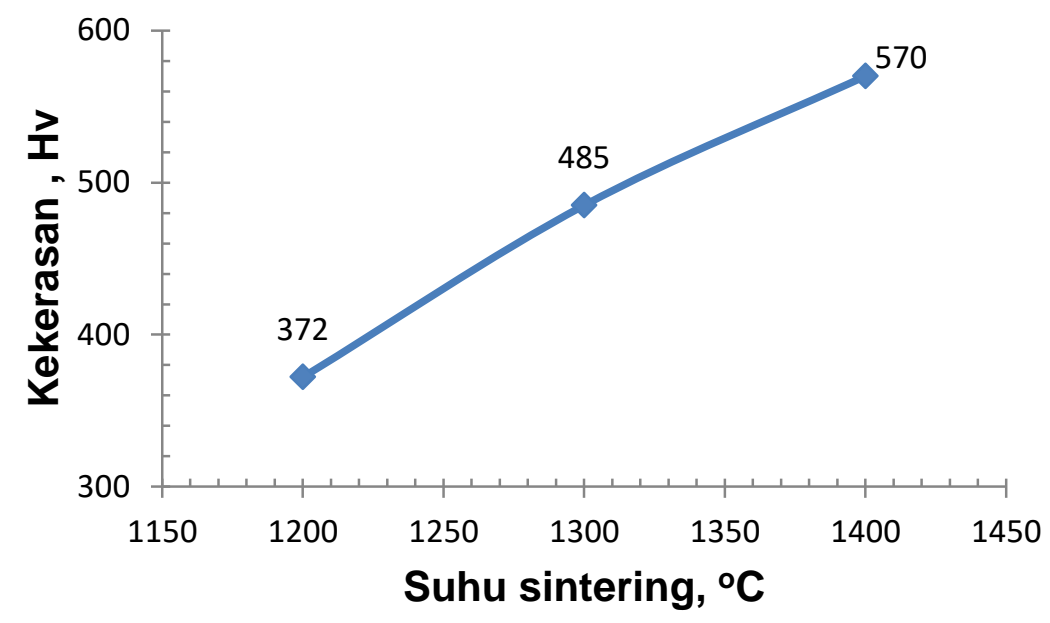

Gambar 2. Kurva hubungan kekerasan terhadap suhu sintering

Dari Gambar 2 dapat dilihat sampel dengan suhu sintering $1400^{\circ} \mathrm{C}$ menunjukan nilai kekerasan tertinggi dengan nilai hardness vikers $570 \mathrm{Hv}$. Nilai kekerasan pada suhu $1300^{\circ} \mathrm{C}$ diperoleh nilai hardness vikers dengan nilai $485 \mathrm{Hv}$. Sedangkan dengan suhu $1200^{\circ} \mathrm{C}$ didapat kekerasan vickers terendah sebesar $372 \mathrm{Hv}$. Bila dibandingkan dengan kekerasan zirkonia atau alumina masih tergolong lebih rendah.

\section{Hasil uji Kuat Tekan $\left(\mathrm{ZrSiO}_{4}\right)$}

Hasil uji kuat tekan dengan variasi suhu sintering di perlihatkan pada Gambar 3 sebagai berikut. 


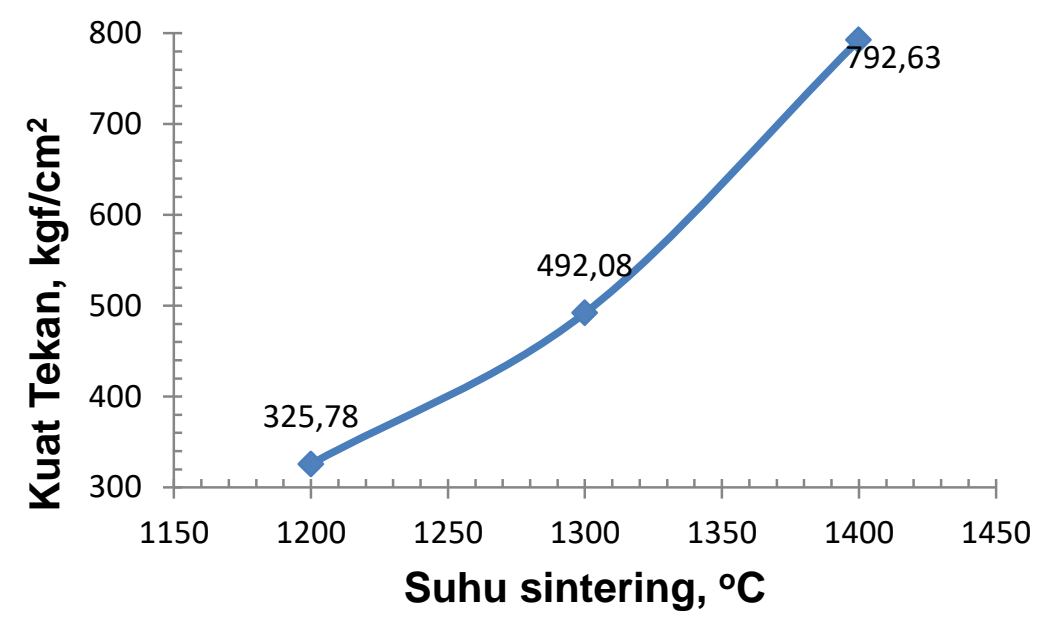

Gambar 3. Kurva hubungan kuat tekan terhadap suhu sintering.

Dari Gambar 3 meunjukkan hasil pengujian kuat tekan bahwa angka berkisar antara $325.78 \mathrm{~kg} / \mathrm{cm}^{2}-792,63$ $\mathrm{kg} / \mathrm{cm}^{2}$. Sesuai dengan niali densitas atau keketrasan, semakin besar nilai densitas nya akan semakin padat sehingga kuat tekannya juga cenderung meningkat denga meningkatnya suhu sintering.

\section{KESIMPULAN}

Peningkatan suhu sintering dapat memberikan pengaruh yang siqnifikan terhadap nilai densitas, keketasan dan kuat tekan. Nilai densitas, kekerasan dan kuat tekan tertinggi dari keramik zirkon silikat tercapai setelah proses sintering pada suhu $1400^{\circ} \mathrm{C}$.

\section{DAFTAR PUSTAKA}

[1] Mulyadi Utomo Agus, Drs. 2007. Wawasan dan Tinjauan Seni Keramik, Institut Seni Denpasar: Paramita.

[2] Aprilla Erryani, Pengaruh penambahan Zikonium silikat sebagai insulator termal terhadap nilai konduktivitas termal liner HTPB, Berita Dirgantara Vol 12 no 4 , Desember 2011, 126-151

[3] Ristic, M.M., Sintering New Developments, Material Science Monogrraphs, vol 4, Proceeding of 4th International Round Table Conference on Sintering, Dubrovnik, Yugoslavia, September 5- 10, 1979,Elsevier Scientif Publishing Company, Amsterdam-Oxford, New York.

[4] German, R. M., 1991, Fundamental of Sintering, Engineering Materials Handbook, vol 4, Ceramic Glases, W.D Nikki, ed. The Materials Informatiaon Society.

[5] Richerson, D.W., 1982, Modern Ceramic Enginerring, p.217 - 239.

[6] S. Abdolazizi, R. Naghizadehb, S. Baghshahic, The Comparison of MgO and TiO2 Additives Role on Sintering Behavior and Microstructures of Reaction-Sintered Alumina-Zirconia-Mullite Composite, ACERP: Vol. 1, No. 2, (Summer 2015) 11-17

[7] Heidy L. CALAMBÁS PULGARÍN and María P. ALBANO, Sintering and Microstrusture of Al2O3 and Al2O3-ZrO2 Ceramics, Procedia Materials Science 8 ( 2015 ) 180 - 189 